\title{
Almanaque: composição de um rosto
}

Almanac: composition of a face

Ernesto Rodrigues

Universidade de Lisboa, Faculdade de Letras, CLEPUL

\section{DoI}

https://doi.org/10.37508/rcl.2021.n46a 456

\section{RESUMO}

Os almanaques visavam atrair diferentes níveis da sociedade: desde tabelas astrológicas aos feriados cristãos, do entretenimento à publicidade, este artigo visa estudar o seu tão significativo papel, para entender a importância destes velhos meios de comunicação.

Palavras-Chave: Astrologia; calendário; entretenimento; publicidade; Almanach illustrado do Brasil-Portugal.

\section{Abstract}

Almanacs were written to appeal to different levels of society: from astrological tables to Christian holidays, from entertainment to advertising, this paper aims to study their significant role, in order to understand the importance of these old media.

KEYWORDS: Astrology; calendar; entertainment; advertising; Almanach illustrado do Brasil-Portugal. 
Variedade e fragmentação requerem escrita sucinta para leitura veloz, mesmo voraz. Mas este pacto é oitocentista, no quadro da nascente Imprensa de massas. Antes, há um tempo medieval, científico, sem a superficialidade das redes sociais deste milénio, que retomam o modus operandi do almanaque citadino e burguês, cuja conectividade se faz com outras publicações e, cada vez mais, com leitores em vários continentes.

Tendo já abordado a sua evolução, em que salientei títulos - em particular, o Almanaque de lembranças e seu fundador, Alexandre Magno de Castilho - e estudei passatempos difíceis como os logogrifos (RODRIGUES, 2021a, p. 157-185), completo agora esse trabalho com uma espécie de arqueologia e teoria de medium particular: na explosão do século XIX, o almanaque transcende o jornal, revista e livro - em que bebe, quando não é expansão daqueles, dentro da mesma empresa -, e, ao contrário deles, pela crescente intervenção de audiências até ali passivas (com inesperada emergência feminina), passa de meio quente, definido de vez no Antigo Regime, a meio frio (McLUHAN, 1977, p. 341-342), ou seja, faz-se espaço de diálogo e colaborações de fora. A qualidade decai, na democraticidade que o liberalismo requer, mas a disseminação do produto e o inumerável das propostas em centenas de páginas dizem bem que novos tempos vinham aí, entretanto ouvidos no telégrafo, telefone e fonógrafo, iluminados pela fotografia e cinema, passeando-se de comboio, metropolitano, bicicleta e automóvel. O Novo Mundo exigia edições próprias; e, sustentando esta aventura, o chamariz publicitário. Eis amostras do século do Progresso.

1. As origens do nome assentam em probabilidades. O Diccionario da lingua portugueza por Antonio de Moraes Silva (1877, p. 92) associa, com pequenas diferenças, almanaque, de al-manach, e calendário, de calendae, não sem evocar D. Frei Francisco de São Luís, que nega a etimologia árabe, dizendo-a "talvez egypcia". Enciclopédias 
tiram a palavra de al-manāh (cálculo, cômputo, quadrante solar), afim de al-men, calendário de previsões astronómicas e atmosféricas. O Dicionário Houaiss da língua portuguesa (2002, p. 209) precisa os étimos árabes al-munākh / al-manākh, significando "lugar onde o camelo se ajoelha; estação, clima; paragem numa viagem”, e, via latim, almanachus, com a primeira frequência almenaque no século XV, em Gomes Eanes de Zurara (c. 1410-1474), Crónica da tomada de Ceuta por el rei D. João I. Assim é, em página sobre os astros, nesta estrutura: "ca acho pollos almenaques, que quando os mouros perderam Espanha” (ZURARA, 1915, p. 173), etc. Raros lembram o celta al mon aght, observação das horas. Mais recente, o Dicionário de arabismos da língua portuguesa (ALVES, 2013, p. 177) traz al-manâh, o clima, o calendário, "obra versando os mais variados temas, incluindo os climas", sem evitar uma já gasta sabedoria de almanaque como "saber superficial".

Nadia Tadlaoui resumiu, a meu pedido, três dicionários de árabe

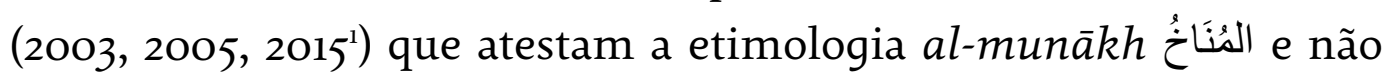

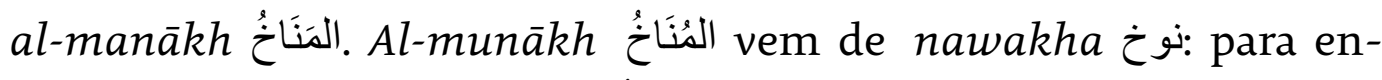

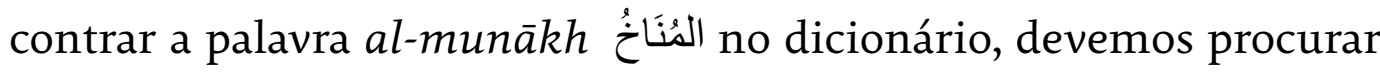
nawakha نُ نntrada que tem todos os derivados. Al-munākh traduz-se como: lugar onde o camelo se ajoelha, lugar de residência, ambiente, lugar não adequado, clima, clima local, preparar o clima adequado, meteorologia, calendário, cálculo, calendário de previsões.

2. Vários dispositivos impressos concorrem na sua configuração. Olhamos para o Calendarium (Veneza 9-VIII-1482) de Johannes

1 Al-monjid Fi Al-Lura wa Al-A¿lām. Dicionário da língua árabe. Beirūt: Dar el-Machreq Sarl, 2003; Ibn Manðor, Lissan Al-¿arabe, Beirut: Dar Sader, 2005; Al-Homșī, A. Salim \& Ḍannāwī, S. ¿Abd Al-lațīf, Ar-rāfid (Dicionário da língua árabe-árabe), Țarābulus: Instituto Novo do Livro, 2015. 
Müller Regiomontanus e para as Horae ad usum Romanum (Paris, Antoine Verard, 20-X-1489), e temos, aqui, Januaris com as festas e santos do mês ${ }^{2}$, algo semelhante às disposições do calendário do Breviário bracarense de 1494 (fólios 1-6). Verard imprimiu outras horae. Mutilado na Biblioteca Nacional de Portugal, Calendarivm romanvm (Lisboa, 1536) traz os santos do dia, sendo mais completo o Calendarivm perpetvvm saído na oficina coimbrã de António Mariz, em 1581 e 1583 , com os santos hispanorum, ano este do Kalendarivm gregorianvm perpetvvm, em Lisboa. Associados ao Martyrologio dos santos de Portvgal, e festas geraes do reyno (Coimbra, 1591), estavam lançadas as bases de foro clerical que chegaram aos nossos dias.

O exemplo cristão, qual pão partido em pequeninos, vinha de Exempla sacrae scripturae ex utroque Testamento collecta (Paris, c. 1473) e de Sermones moralissimi atque ad populum instruendum utilissimi supra evangelia dominicalium (Paris, c. 1476). O conteúdo de Prouerbios de dõ yñigo lopez de mendoça: con vn tractado de remedio contra fortuna que esta pusto en fim (Toledo, c. 1500) evoca muito do que será o assento em máximas moralizadoras.

A Idade Média serve-se também dos autores enquanto únicos cientistas, seja na medicina, na história, na botânica, etc. E. R. Curtius (1986, I, p. 116) carreia "sententiae et exempla" enquanto "source de savoir" e "trésor de sagesse", recusando a frivolidade de pensamento atribuída ao almanaque. Noutro subcapítulo, "Le livre de la nature" (II: 31), ocorre-nos a infinita distribuição de bens que vamos encontrar em livro singular, livro do mundo e que é um mundo: "Hic liber est mundus", diríamos com John Owen (1563?-1622; CURTIUS, 1986, II, p. 35). Recolhas de histórias, fábulas, centões, conselhos, Loci commvnes sententiarvm et exemplorvm (Coimbra, 1569), tábuas de

2 Reprodução em Secretaria de Estado da Cultura/IBNL. Os incunábulos das bibliotecas portuguesas. Volume I. Lisboa, 1995, p. 222. 
santos (1572) ou Calendarivm perpetuvvm (Lisboa, 1573), que muitos imprimiu João Barreira, serão manancial. Mesmo as gravuras parecem tiradas desse Quatrocentos inaugural.

Especifica-se uma nova ciência nas tabelas astronómicas do zacutiano Almanach perpetuum (25-II-1496) ${ }^{3}$. Podemos associá-lo aos vários Astronomicon ou a Johannes Angelus, Astrolabium planum in tabulis ascendens (Veneza, 1494), e, em data ignorada do séc. XVI, ao Regimento do estrolabio $\varepsilon$ do quadrante (...). Nos quase duzentos anos da dinastia de Avis, até à leitura errada que D. Sebastião faz do cometa ( $a$ cometa, como então se dizia) sobre o céu de Lisboa em finais de 1577 - que o levou a acometer contra os mouros, a cometer o desastre de Alcácer Quibir -, teve grande peso a astrologia 4 , incluindo horóscopos, parodiados no Júlio César Machado de Da loucura e das manias em Portugal (1870). Nem por isso escasseia, hoje, inclusive nos media digitais, todo o tipo de oráculos, profecias e previsões, em que só as meteorológicas avançaram.

Vem, a par, a imensidão de prognósticos, lunários, folhinhas e braquilogias astrológicas (há uma Brachylogia em 1646), conjugados, para dar só um exemplo, no Almanach prototypo e exemplar de prognósticos, com particulares ephemeridas das conjunções, $\mathcal{E}$ aspectos dos planetas, eclypses do Sol, $\mathcal{E}$ Lua, $\mathcal{E}$ pronostificação de seus efeitos pera o presente anno de 1645 (Lisboa, 1644).

Afim, a ideia de repertório/reportório vinha do séc. XV: Pedro del Monte, Reportorium utriusque júris (Pádua, 16-XI-1480); anónimo,

3 Estranhe-se, por isso, quando José Leite de Vasconcelos (1980, p. 222) corrobora o Dicionário... de Inocêncio, VIII, p. 48, XII, p. 227, segundo o qual “a tentativa mais antiga da publicação de um almanaque em Portugal data de 1745".

4 Ver António José Saraiva, História da cultura em Portugal. Vol. III. As navegações e as origens da mentalidade científica. Edição de Ernesto Rodrigues. Lisboa: Gradiva, 2010, p. 45-48. À frente, Garcia de Resende, Gil Vicente e outros criticam estas soluções. 
Repertorium de pravitate haereticorum (Valência, 16-IX-1494), e, de Petrus Berchorius, Repertorium morale (Nuremberga, 4-II-1499). Donde, as inúmeras edições de repertórios e do Reportório dos tempos (1518) ao longo do século XVI, a par de singular Veritatis repertorium (Coimbra, 1567), oferecido ao cardeal D. Henrique.

Crescia, já, uma variante significativa. A qualidade dos produtos agrícolas é exaltada no Hortus sanitatis (1490) e em demais horti. Trata-se de um segmento fundamental, até aos sobrevivos de hoje, intermediados pelo Almanaque do cultivador para 1856 e para 1857 (Lisboa, 1855, 1856), qualificados no nome de J. Félix Nogueira, que já no Almanaque democrático para 1852, 1853 e 1854 teorizara sobre a importância dos mesmos, inspirados no estrangeiro, e redigira artigos notáveis sobre políticos estrangeiros.

3. Falámos, até aqui, de um objecto circunscrito à corte e adjacências, que, todavia, podia figurar - sem a ela chegar - a vida camponesa, desde o tipo de casas às estações e culturas. Os trabalhos agrícolas vinham já representados, para cada mês, na catedral de Amiens (séc. XIII), na sequência de textos do século IX (LE GOFF, 1999, p. 119-120). Ora, o tempo camponês, que não é ainda destinatário, tal o analfabetismo e baixo nível de vida, jamais acertaria com informação desejavelmente fidedigna, se continuasse a guiar-se por relógios de sol, clepsidras e sinos das igrejas. Este modo de vida não terminou de vez, tantos os hábitos medievais em certas comunidades, obedientes a toques e liturgias. Mas até estes passaram a exigir uniformidade horária, o que, desde meados de Trezentos, constitui uma alteração decisiva. Sem relógio mecânico (régio e público, em finais do séc. XIII-XIV), até chegar ao individual, miniaturizado (finais do séc. XV), ao de pulso (séc. XIX) e aos telemóveis, não éramos o que somos; e nem os almanaques consideravam a precisão dos minutos. 
A temporalidade da vida cristã, desde o nascimento de Jesus, lê-se no Horologium deuotionis circa vitam Christi (1500; Évora, inc. 2). O sinal de parágrafo, precedendo título e textos brevíssimos, marca as etapas de Quem se deseja também visível em gravuras ingénuas. Falta passar do latim ao vulgar. O paradigma suscitará almanaques de teor religioso mal estudados, em que salientaria o de S./Santo António, desde 1898 (até, pelo menos, 2015), que atingiu quatro mil exemplares.

O tempo burguês (LE GOFF, 1999, p. 18) das cidades e do comércio preenche melhor as etapas da vida e do dia, alargando este a horas sem sol - por que se regia o tempo lento rural -, por razões económicas, e mais com a Revolução Industrial. As medidas são outras, surgem regulamentos, irrompem protestos, enquanto o século XVIII ainda impõe listas de dignitários, uma espécie de quem é quem, e respectivos endereços, para visitas sociais. Sem recusa de sugestões cristãs, a burguesia ascendente quer ir além, substituindo, no justo lazer, jogos físicos camponeses por actividades intelectuais. Anedotas quinhentistas exigem entendimentos agudos; exigem mais, na profusão barroca - em que ainda se canta um relógio de areia, de sol, mas emergem relógios falantes, de algibeira, mostrador com Cupido5 ${ }^{5}$, e novas dos trabalhos mafrenses de D. João V -, adivinhas, enigmas, labirintos, lipogramas...

5 Além de D. Francisco Manuel de Melo, encontramos referências em Tomás Pinto Brandão, José Correia de Brito, Félix da Silva Freire, Francisco Mascarenhas Henriques e um mais quantioso António da Fonseca Soares, que se repetiu em castelhano. A força do objecto vem até ao último quarto de Oitocentos: Gonçalves Crespo dá quadro de salão espelhado no esmalte da tampa. Primeira quadra do soneto de "O Relogio / (No álbum do amigo E. Burney)": "Eburneo é o mostrador: as horas são de prata. / Lê-se a firma Breguet por baixo do gracioso / Rendilhado ponteiro; a tampa é enorme e chata: / Nella o esmalte produz um quadro delicioso." (A republica das letras, 3, Porto, Junho de 1875, p. 37). Júlio Dantas diz o relogio um "velho assassino", pois nos engole, qual Crono (Gabinete dos reporters, Lisboa, 22-IX-1895, p. 3). 
Com a mudança nos hábitos e a vida mais apressada sob o signo do relógio, passa-se, em Oitocentos, da folhinha ao omnipotente almanaque:

A velha Folhinha era uma modesta amiga sem pretensões, serviçal e fiel, que a toda a gente apontava, a troco d'uma pobre moeda, os dias dos mezes, os nomes dos santos, as festas e os feriados, as luas e os jejuns. Era uma coisa que limitadamente correspondia ás necessidades do tempo, que não eram muitas. Bons tempos esses, em que cada qual se contentava com saber em que dia do anno cairia a Paschoa, ou a quantos de Maio seria o Corpo de Deus!

Mas os tempos mudam, e tudo muda com os tempos. A vida, de pachorrenta e conformada que era, tornou se inquieta e ambiciosa. Toda a gente, que d'antes andava por essas ruas em passo de procissão, e tratava dos seus negocios sem barulho, começou de repente a atarefar-se e a correr, (...).

(...) Agora, ao entrar na vida, cada qual se julga obrigado a saber o que o Diabo não soube. E foi para atender a esta necessidade urgente, que se inventou o Almanach.

O Almanach tudo diz, tudo mostra, tudo desvenda, tudo patenteia, tudo explica, tudo aclara, tudo ensina.

Tem tudo quanto tinha a Folhinha, augmentado de tudo quanto encerram os Tratados. É informativo, é elucidativo, é instructivo, é recreativo. É Borda d'Agua e Larousse. É Seringador e é Encyclopedia. (MESQUITA, 1902, p. 7-8).

Os almanaques tornam-se compêndios do passado, meras antologias apostas ao calendário (nem sempre obrigatório), com a pecha de futurar, economicamente seguros enquanto projectos institucionais, de livraria, de jornal ou revista, de profissão, grupo, congregação, programa social ou político, de sujeito individual, localidade. Absorvendo pepitas nas folhas de instrução, de recreio e noticiosas, essas variedades enriquecem-se, num segundo mo- 
mento, em colaborações actuais, graciosas, do poema à charada, suscitando participação cada vez maior, em tiragens só ultrapassadas pelos diários generalistas. Acompanhando-nos no dia-a-dia, era um ano inteiro ${ }^{6}$ com o único livro que as famílias de menores recursos possuíam.

Havia colaborações especiais, e não só de textos inéditos a serem procurados pelas futuras edições críticas. Em domínio que vai além da iconografia, os de Rafael Bordalo Pinheiro pediam demora. O Almanach de lembranças, antes ainda de chegar a meio caminho, funcionava como sintoma social, no olhar crítico de J. Leite de Vasconcellos ${ }^{7}$.

Congraçando uma causa própria e iniciativa individual, veja-se como Guiomar Torresão publicita, em Ribaltas e gambiarras/Revista semanal, que dirige, o seu Almanach das senhoras para 1882, em 11. a edição (e que vai entrar pelo século XX). Aumenta o número de colaboradores, com nomes cimeiros de Portugal e Brasil, melhora o grafismo, apoiado em imagens e retratos fotográficos,

6 Nestes dois séculos, houve almanaques mensais, dentro ou fora do espírito originário (neste caso, mantinha-se o título). Aqueles pouco vingaram, sendo duvidoso que algum mais profusamente anunciado tenha saído. É o caso do Almanak mensal, caracterizado em página inteira da Revista universal lisbonense, tomo III, $1850-1851$, n. 23 , p. 276.

7 “Scintillações / I / Soneto": "Somnambulas do amor, virgens doiradas, / que sois de poetas vãos, vãs esperanças: / ó labios matinaes, mimosas tranças, / braços de neve, faces perfumadas: // por vós, andam perdidos nas estradas / os dandys e os vadios, ó creanças; / por vós, sonetos mil, canções, charadas, / vão sempre p'ra o Almanach de Lembranças. // Valeis das orientaes toda a riqueza; / estaes nos thronos de ouro da poesia, / como uma bella e olympica princeza; // mas teríeis o dobro da valia, / se gastasseis, ó anjos da beleza, / pó de arroz com mais economia..." (O academico / Revista quinzenal litteraria, Porto, n. ${ }^{\circ}$ 6,1878, p. 48). 
sobem as tiragens, e, para a secção de problemas, convidou "um ilustre lente de mathematica, (...). Os problemas do almanach para 1882 dividir-se-hão em duas series, sendo uma exclusivamente para o Brazil." (n.o 24, 15-V-1881, p. 191). Ora, agilidade intelectual não basta - nem citar vencedores na edição do próximo ano -, e segue a lista dos principais prémios, abrindo por argola de prata para guardanapo.

Mais, e entramos no osso da questão, sem o que não existiam certos media: a publicidade. Tipicamente no final, mesmo em papel colorido, Guiomar Torresão sabe o que fazem na Europa e América, pelo que vai intercalar anúncios no miolo, contíguos ao texto, segundo diagramação, preços e locais de venda desse espaço, em Lisboa e Porto; no último número de Ribaltas e gambiarras (n. ${ }^{\circ} 26,29$ V-1881, p. 208), refere os do Rio de Janeiro. Tudo isto é pensado com antecedência.

Estão por estudar as diferenças entre as edições destinadas a Portugal e colónias e as que seguiam para o Brasil. A melhor solução foi encontrada pelo Almanach illustrado do Brasil-Portugal (Lisboa, 1900-1902: para o anno de 1900, de 1901, de 1903). O calendário coloca lado a lado os santos e festas litúrgicas atinentes aos dois países, aqui residindo algumas pequenas diferenças (que desrespeita na $3^{\text {a }}$ ediç̧ão, com calendário só português), já maiores nos eclipses visíveis em Lisboa e no Rio de Janeiro. Há também distinção em dias santificados e nos feriados, seguindo-se os preços dos correios e telégrafos, a tabela de preços dos teatros, nascimentos e ocasos do Sol, as passagens marítimas, tudo intervalado por poemas de nomes em vista e gravuras. Sucede um balanço dos principais almanaques do tempo (inaugura o ainda hoje resistente Seringador, já em 35. edição) e acrescenta-se prosa de Eça. Interessa "O gabinete portuguez de leitura no Rio de Janeiro / (A primeira acta)" ( $\mathrm{p}$. 48), seguido de motivos brasileiros. Olavo Bilac e poucos mais não 
equilibram a antológica portuguesa, mas a publicidade também é só lusitana. Virá imensa publicidade brasílica no almanaque para 1901, que indica os respectivos consulados, e traz os nomes de Coelho Netto, Cruz e Sousa, etc.

Quanto mais crescem as assinaturas, mais embaratece o produto. Mas, se isso é uma evidência, não é menor a falta de comércio e negócio em Portugal, com prejuízo geral. A fé e a publicidade suportam alguns projectos; mas, ironia!, ou maleita dos tempos, nem o Almanach da agencia primitiva de annuncios (Lisboa, 18701877) - que, dizia Júlio César Machado (1872, p. 61), era o único de todos os livros "que me parece verdadeiramente bom para se lêr"-, durou bastante.

O almanaque serve, enquanto espaço de convergência, aos quatro modelos de comunicação: ao de transmissão simples, linear, como qualquer notícia cognitivamente entendida; ao ritual ou expressivo, por uma lógica composicional desde os pioneiros, aguardada, tanta vezes ansiosamente, por destinatários reverentes; ao publicitário, seja pela autopublicidade, pela que outras publicações lhe fazem, em notas e recensões, mesmo partilhas, e por incluir massa compacta de anúncios, como nenhum outro meio coetâneo; enfim, ao modelo de recepção, quando se obriga o leitor a descodificar alguns textos literários e mesmo de uma ciência doméstica, sem já falar na dificuldade de resolver problemas que nos obcecam durante meses, até às soluções no volume seguinte.

Pela filiação e desenvolvimentos multidisciplinares, o lugar-comum que desvaloriza os almanaques nasce da ignorância. Na gradual compactação de matérias, de iconografia em vários estádios, de linkagem entre edições, nos processos, embora nem sempre coerentes, de hipertextualização, na miríade de parágrafos curtos, copiados 
e colados algures, pressente-se algo que, nos anos 60 do século XIX ${ }^{8}$, se começava a atribuir ao telégrafo eléctrico do futuro, dito internet: a instantaneidade e interconectividade universais. Se, ao tempo, as comunicações ainda diferiam o instantâneo, resolvido em edições diárias de algumas folhas de Imprensa, aceitemos as ligações atlânticas da rede postal luso-afro-brasileira via almanaque como anúncio do moderno Facebook.

RECEBIDO: 05/06/2021 APROVADO: 05/08/2021

\section{REFERÊNCIAS}

ALVES, Adalberto. Dicionário de arabismos da língua portuguesa. Lisboa: Imprensa Nacional - Casa da Moeda, 2013.

CURTIUS, E. R. La littérature européenne et le moyen-âge latin. I, II. Paris: PUF, 1986.

8 Ver "O jornalismo no ano 20oo", Jornal do comércio, Lisboa, 25-II-1868, in RODRIGUES, ${ }^{22021 b, ~ p . ~ 901-903 . ~ E x c e r t o s: ~ " H a ́ ~ f o m e ~ e ~ s e d e ~ d e ~ n o t i ́ c i a s: ~ t o d o s ~ q u e-~}$ rem saber tudo - o que pode e deve saber-se e o que não pode nem deve saber-se -, a máquina reproduz em minutos o pensamento, para ser transmitido a todos os pontos da terra, (...). // Cada cidadão fará um jornal: o artigo de fundo constará sempre das notícias da sua vida pública e íntima. Cada um informará o respeitável público das horas a que se levanta da cama, tendo previamente declarado como passou a noite; noticiará a que horas almoça e o que almoçou; referirá, minuciosamente, o seu jantar e as pessoas com quem jantou; dirá se o jantar estava bem cozinhado; contará se o seu gato miou, se o cão ladrou, se o papagaio está incomodado; narrará todas as miudezas da sua casa, não escapará à publicidade a mínima dor de cabeça ou de estômago; se estiver doente, publicará um boletim das moléstias, não só a seu respeito, mas de toda a sua família; enfim, todas as circunstâncias da vida caseira, as mais íntimas, serão contadas no jornal, acomodando o estilo aos factos. // (...) O telégrafo eléctrico generalizar-se-á, cada cidadão terá o seu telégrafo em correspondência mútua, de maneira que em um minuto se saberá o que se passa nos pontos mais afastados e, em Lisboa, se poderá saber, de instante a instante, até à vida caseira do mais boçal esquimó; com o que os povos hão-de folgar, deleitar-se e instruir-se." 
Dicionário Houaiss da língua portuguesa. Lisboa: Círculo de Leitores, 2002.

LE GOFF, Jacques. Un autre moyen âge. Paris, Gallimard, 1999.

MACHADO, Júlio César. Á lareira. Lisboa: Livraria de Campos Junior Editor, 1872.

McLUHAN, Marshall. Pour comprendre les médias. 2. ${ }^{\mathrm{a}}$ ed. Paris: Mame / Seuil, 1977.

MESQUITA, Alfredo, “Juizo do anno”, Almanach Illustrado do BrasilPortugal para o anno de 1903. Lisboa, p. 5-9, 1902.

MORAES SILVA, Antonio de. Diccionario da lingua portugueza. 7. ${ }^{\mathrm{a}}$ ed. Lisboa: Typographia de Joaquim Germano de Souza Neves, 1877.

RODRIGUES, Ernesto. Cultura literária oitocentista. 2. ${ }^{\mathrm{a}}$ ed. Lisboa: CLEPUL, 2021a.

RODRIGUES, Ernesto. Mágico folhetim. Literatura e jornalismo em Portugal/Crónica jornalística. Século XIX. 2. a ed. Lisboa: CLEPUL, 2021b.

VASCONCELOS, José Leite de. Etnografia portuguesa. I. Lisboa: INCM, 1980.

ZURARA, Gomes Eanes de Zurara. Crónica da tomada de Ceuta por el rei D. João I. Edição de Francisco Maria Esteves Pereira. Lisboa: Academia das Sciências de Lisboa, 1915.

\section{MinicuRRículo}

Ernesto Rodrigues é professor associado com agregação na Faculdade de Letras da Universidade de Lisboa. Últimos títulos: Perseu, poesia, 2020; A terceira margem, romance, 2021; Teatro, 2021; Portugal segundo Trás-osMontes e Alto Douro, ensaio, 2021; Dániel Levente Pál, O Oitavo Distrito de Deus, tradução do húngaro, 2021. 